\title{
Malthus en la literatura popular del siglo XIX*
}

F uimos un pueblo folletinizado. Antes de vivir 1 malthusianamente, Occidente urdió una naturaleza folletinesca, fabuló nuevos orígenes y, señalamiento estratégico, trazó una arquitectura folletinesca de la sociedad, que no fue nada más un simple desarrollo comercial del relato en la sociedad. Literatura de una cotidianeidad que se volvió alouvi, el folletón -lugar de matrimonios, abrazos, risas, muertes- sigue siendo, al parecer, la civilización a la que pertenecemos. Relato de la prolijidad, esta combinación mercenaria y heterónoma fijó nuestro destino, codificó nuestras costumbres, estatuyó nuestros comportamientos conyugales De hecho, estamos obligados a conocer las leyes de la población que regulan el curso de la novela cotidiana. Sin semejantes lecturas, que son el bagaje cultural de la especie industrial, la anatomía del siglo XIX se nos revela como una ciencia falible.

El folletinista no es un estadístico, un balzaciano, sino un casamentero preocupado por una sola familia, y numerosos novelistas se pusieron a leer, a la manera de Richenbourg -voluntariamente autoritario, involuntariamente caricaturescocomo si supieran un poco más que nosostros sobre la cuestión del matrimonio. La textura del folletín aparece como un remiendo de gacetillas periodísticas, de fragmentos judiciales reunidos en conglomerados en el curso de múltiples capítulos; pero en este universo, hecho aparentemente de ruidos, actúa de principio a fin una conciencia moral, una lógica matrimo-

\footnotetext{
* Traducción de Julián Meza.
} 
nial ${ }^{1}$. Profesoral y didáctico, el epílogo, bella arrogancia nupcial, nos mantiene dentro del código napoleónico. En lo sucesivo, al existir por derecho propio y sin competencia, el matrimonio se opone a la miseria y a la violencia, suscita el desarrollo del bien, verifica mecánicamente el poder de las buenas costumbres. Como realidad incontorneable de la vulgata folle-

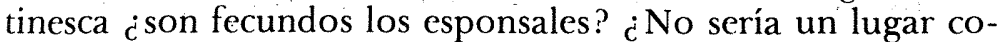
mún interrogar a estos relatos acerca de la problemática malthusiana?

Quintaesencia de las inquietudes filantrópicas, el folletín ignora todo problema político, económico, demográfico y, si no es antes del Segundo Imperio, desconoce el nombre mismo de Malthus. Sólo Sue, legatario folletinesco, imaginó una propedéutica antimalthusiana al leer, según parece, a Pierre Leroux. $^{2}$ En las aguas mezcladas de la narración cotidiana y el socialismo Martin, l'Enfant trouvé (Martin, el niño hallado) refuta la metáfora del banquete, que es una escena traumática, no en el plano de la población, que es un plano abandonado, sino en el de la caridad. ${ }^{3}$ Los años que van de 1840 a 1849 , los cuales

- Al seguir en esto a Bértillon los poblacionistas hicieron, en nombre de la moral, mucho ruido contra el folletin. Pero sus ataques sólo remedaban las expecta tivas, muy envejecidas, de los juristas y otros consejeros espirituales (por ejemplo: el (aso Jobard: un asesinato en el teatro de los Celestins en Lyon, en 1852). Ya en $1842 \mathrm{el}$ incritable Mirecourt sermoneaba a los literatos. Cf. Le liutenant de la Minerve (El teniente de la Mineria)... Por otra parte los periódicos populares reñian a menudo según este argumento de depravación moral: "Es con este tipo de iniciativas (rifas en beneficio de los niños pobres e incurables) y no con novelas de un gusto tan equivoco como la Résurrertion de Rocambole (Resurrección de Rocambol) con lo que se inspira a las masas el amor a las virtudes de la familia y el respeto al hogar doméstico." Le Journal de la Semaine num. 597 del 23 de noviembre de 1865 . A este respecto la lectura de L'Ouvrier es muy sintomática.

2 Por lo menos de la seric de artículos publicada, en 1842, por la Revue Sociale, que apareció a continuación con el título de "Malthus y los economistas o ¿'siempre habrá pobres?" Leroux da ahí la sustancia del programa seguido por Sue desde Les mystères de Paris (Los misterios de París): "Es la capital la que mata a la humanidad. La mata de mil maneras: la mata con las enfermedades, la mata con el crimen, la mata con la prostitución, la mata con todas las plagas del cuerpo y del alma" (edición de 1849 , p. 176$)$.

${ }_{3}^{3}$ Martin, l'Enfant trouvé (antaño Mémoires d'un balet de chambre (Memorias de un ayuda de cámara) y, más tarde, Les Misères des enfant trouvés (Las miserias de los niños hallados) de la ed. Vict. Benoist, sin fecha) se inició en 1846 en el Constitutionnel. El artículo de Leroux "La economía política y el evangelio. A propósito de una conferencia del R. P. Lacordaire" fue editado en febrero del mismo año. "¿Siempre habrá pobres?" se editó en abril. 
constituyeron un decenio batallador, disertaron sobre la terapéutica malthusiana y, según su costumbre, Sue, copista teatral de lo audible, merodea en los escritos de actualidad con el fin de establecer una realidad folletinesca en la que la caridad se volverá, como corolario de los textos de Leroux, lo imaginario democrático. Como amontonamiento desordenado y glotón todo folletón es el relato de la abundancia compiladora, pero de ninguna manera de la fertilidad, aunque en esos tiempos de esperanza todo socialista tiene que cohabitar con el folletinista. Martin, l'Enfant trouvé es una novela concebida en 1846, cuando el campo de validez de la interpretación folletinesca conserva la huella embrolladora de Leroux, y Malthus, hombre de una sola frase, que es nuestro funesto destino, se afirma en ella como un clínico bárbaro. Jamás insistiríamos demasiado en el carácter desapegado, cesible de la imagen del banquete. El hecho de que esta haya sido suprimida después no podría inducir al folletinista a una nueva lectura. ${ }^{4}$ Perito en deslindes que vuelve a asentar los crueles límites de la aristocracia, Malthus simboliza para siempre el salvajismo de las clases acomodadas:

(...) -sí, la caridad es estúpida; sí, la caridad es peligrosa; sí, la caridad es detestable; y no soy yo quien dice esto, Señores, sino los grandes espíritus, cuyas ciencias y cuyo genio son admirados en toda Europa, y lo que dicen lo prueban con hechos y cifras inexorables. Estos genios son mis santos; sus escritos son mi catecismo y mi Evangelio; y como buen creyente sé mi Evangelio de memoria. He aquí lo que dice textualmente Malthus... San Malthus, uno de los más admirables economistas de los tiempos modernos. Escuchad bien, Señores: [sigue la frase del banquete] ¿Es claro, Señores? -añadió el conde con una alegría amarga y triunfante. Y luego: -iCómo! Cuando esta excelente naturaleza, sabia madre... de policía, encarga a la dama Miseria arrojar a este exceso de vulgo ciría yo, por una tonta caridad, a contrariar las instrucciones de la naturaleza?... Vamos, pues, Señores, eso da pena. (...) es una excelente lectura para disfrute de los propietarios. Con esta sana lectura fortalecerán la conciencia de sus derechos. También encontrarán ahí estas pala-

${ }^{4}$ Con esto mismo Sue le da la razón a Garnier: "Esta frase (...) sufragó las ampulosidades de todos los reformadores de segundo orden": J. Garnier, Du principe de la population (Sobre el principio de la población), París, 1857, p. 171. 
bras, que los invito a recordar cuando el demonio de la caridad los tiente. Que cada uno, en este mundo, responda de él mismo y por él mismo. Peor para aquellos que están de más aquí abajo. Habría mucho que hacer si se quisiera dar pan a aquellos que gimen de hambre. Quién sabe si aún quedaría bastante para los ricos, pues la población tiende sin cesar a rebasar los medios de subsistencia. La caridad es una locura, un estímulo para la miseria... (...) Malthus era a la vez un hombre de genio y un hombre excelente. No tenía nada en común con esos estúpidos e insolentes reformadores contemporáneos que sueñan con la luna y con lo que debería de ser, en lugar de soñar con lo que es. Maithus, que sabía la verdad de las cosas, no quería embaucar, engañar a nadie. Lógico riguroso, convencido de que las masas han estado, están y estarán siempre destinadas a la suerte más miserable, en su admirable libro prohibió scveramente a los pobres tener hijos. Y tiene razón. ¿ Para qué sirve la simiente de estos muertos de hambre? Marcus, discípulo de Malthus y de Adam Smith, fue otro gran economista, más consecuente todavía. Valientemente propuso la supresión de los hijos de los pobres. Es muy simple: la naturaleza no quiere el estorbo del vulgo y la mortalidad hace las veces de agente de la policía. ${ }^{5}$

Este apólogo, que es una reescritura del Antiguo Régimen, será como una espina clavada en la carne del relato. A través de él, el conde y sus congéneres se atribuyen, de nuevo, un privilegio de universalidad. En la cerrada promiscuidad, en el helado ceremonial de estas cuantas palabras DuriveauMalthus ${ }^{6}$ afirma, con la aridez de una proeza de ujier, la inexistencia y la invalidez de una clase; amenaza con la proscripción de todos los plebeyos, purga a la tierra de estos miserables, conducidos así a la nada. Como máquina de guerra, la

${ }^{5}$ E. Sue, Martin, l'Enfant trouvé, cap. VIII.

El conde Duriveau cita, además, a Say y a Ricardo, resume asi "esta profesión de fe de un gran propietario": “(...) es preciso (...), bajo el pretexto de la caridad, de la piedad, no hacer ninguna cobarde concesión, que serviría como arma contra nosotros, pues compadecer a aquellos que sufren es acusar indirectamente a la sociedad y la sociedad no puede equivocarse", y concluye con el "iamordazamiento indefinido de la bestia!"

${ }^{6} \mathrm{Y}$, sin duda alguna, Duriveau-Duchâtel, ampliamente denunciado por Leroux. " ¿Dar limosna? - exclama el señor Duchâtel, que resume la escuela de Malthus¡ni pensarlo!" 
empresa de Sue se las arregla contra esta codificación de un poder que racionaliza una condena a muerte. El sistema de citas, de incisiones regulares, de marcas rítimicas es una simplificación devastadora que funda el desarrollo dramático. Como florescencia de la emoción, Malthus no puede ser oído, apreciado, juzgado fuera del teatro de los sentimientos. La alquimia folletinesca quiere ser polémica y, por oposición a sus formulaciones económicas, ambiciona la primavera proletaria, promete nuevas tierras más allá de la frontera malthusiana. Con Sue el novelón aspira a conservar un discurso admisible por todos, adquiere un poder extensivo y comprensivo que da cuenta de los mecanismos sociales y, a continuación, el texto de Leroux, convertido en entidad folletinesca, conoce un nerviosismo y una densidad únicos. Al argumentar Malthus contra el fundamento mismo de todo relato cotidiano: la oficiosidad fraternal, el epílogo, sentimentalismo manufacturador de cierto socialismo, vuelve a encantar al mundo para hacerlo habitable y proclama un igualitarismo de esencia melodramática. La modernidad folletinesca, lectora republicana de Leroux, afronta en Malthus a un enemigo de clase.

Como buen hombre que era, el autor de los Mystères (Misterios) creyó que el socialismo tenía en la novela -territorio privilegiado de las formas de iniciación en un porvenir proletario- una promesa de nacimiento. Encerrarlo en el estrecho marco del reformismo folletinesco, paraje funerario de las violencias obreras, equivaldría a olvidar que una nueva lógica se impuso con el folletín. Sus escritos fueron leídos como melodramas didácticos, y al mismo tiempo que reprueban a Malthus niegan, anticipadamente, cualquier generosidad a los escritos de Montépin, Navery, Lamothe, Féré, etc. Con estos manufactureros de obediencia católica el folletón ya no elogia las reivindicaciones y, como validación del discurso industrial, es una imagen de marca del sistema imperial que se vuelve engaño para comerciar con los proletarios. En lo sucesivo, en el seno de esta totalidad unificada y sin alternativa, la caridad es un fantasma que no puede ser adornado, pues se hace coextensivo a la existencia misma del relato. Como seducción fabulosa y proceso disciplinario conforta la pasividad política e instala en la puerilidad a aquellos que fueron abandonados por Mal- 
thus. Esta crianza supone una moral, que es un noble descreimiento meritorio:

(...) no se dejen degradar por el vicio, no se dejen envilecer por los consejos de la miseria, los cuales a veces son pérfidos. Sean todos ustedes buenos pobres y verán la caridad de los ricos derramarse hasta el desbordamiento sobre todas las miserias. Lo que cierra los corazones y las bolsas, lo que desalienta aun a la buena voluntad son los errores y defectos de algunos pobres. Cuando vamos a pedir, a interceder en su favor con los ricos (...) también se nos dice: "Pero sus pobres tienen defectos, son pobres por su culpa, etc, etc." Nosotros los defendemos, clamamos acaloradamente por su causa, pero algunas veces estamos obligados a bajar la vista y a decir en voz muy baja y a nuestro pesar: ¡Ay! sí, en algunos casos es verdad... ¡Oh! por lavor, ya no nos inflijan esta pena, ayúdennos un poco a hacerles el bien, traten de corregir sus faltas. ${ }^{?}$

Así, la literatura cotidiana legitima una concepción aristocrática y, como autoridad de la beneficencia, es ajena a la crueldad malthusiana. Operativa y de ninguna manera conmovida por las condiciones de la población, expresa una fuerza política y no un dato demográfico.

Evidentemente el folletín casi no festeja el matrimonio entre los pobres, sino que más bien condena las veleidades de su unión libre. Algunos relatos se inquietaron acerca de las realidades de la familia obrera, pero con simples comentarios anecdóticos. Al evocar la carestía de las rentas, que es una insolente

7 Mullois: Livre des classes ouvrieres et des classes soufrantes (Libro de las clases obreras y de las clases que sufren), París, Dillet, 1856, pp. 45-46. El socialismo lacrimoso de Eugène Sue, que es una réplica a los ágapes homicidas de Malthus, será suplantado por un sistema caritativo que combate, de manera sospechosa, el lujo. "La caridad es la puesta en práctica de lo mejor del Evangelio. La satisfacción que procura torna despreciable los poderes del lujo, y la sociedad dispone con ella de una poderosa palanca, que le faltó a la sociedad antigua contra la corrupción de las costumbres. Es la ciencia moral de las compensaciones. Con la caridad la fortuna se vuelve una letra de cambio librada por el pobre a beneficio del rico. Tenemos en el cielo nuestra cuenta corriente; tratemos de que, por nosotros mismos y por el interés general, ;el artículo beneficencia haga olvidar el artículo prodigalidades!' Notre ennemi le luxe (Nuestro enemigo el lujo), $\mathrm{Pa}$ rís, Fourne, Jouvet, 1869, p. 289. Los textos de Mathilde Bourdon reúnen, entre otros, los datos del problema. 
plaga, Paul de Couder asienta la respuesta de una obrera casada desde hace tres años y que no ha tenido hijos:

¿Qué quiere usted? - respondió la joven mujer, a la vez que desplegaba la mano en torno a ella-, ¡estamos tan estrechamente alojados! ${ }^{8}$

Como castidad malthusiana, la abstinencia proletaria marca incidentalmente a algunas novelas y, más durablemente, a las de Souvestre, quien se burlaba de los filántropos: preparadores anatómicos que acuchillan con placer cadáveres miserables. Lo mismo ocurre con el señor Lormier:

$\mathrm{Al}$ permitirle el matrimonio a la gente que no tiene nada se compromete el porvenir de las sociedades, se agranda la plaga del pauperismo. La manera de no esperar ninguna felicidad ni ningún reposo consiste en dejar que nazcan cerca de cada pan, como dice Malthus, ¡tres hombres que se lo disputarán! Al igual que los derechos políticos, el matrimonio debería ser un privilegio. Pero no: se le niega al pueblo el sufragio universal, pero se le concede la propagación universal; se le prohíbe hacer un diputado, que no le cuesta nada, y se le permite hacer niños que hambrean a la sociedad. Quisiera que un hombre no tuviese derecho a tener un hijo sino hasta después de haber depositado una fianza que asegurase los medios para alimentarlo. Pero dado que las leyes no han tomado ninguna precaución contra esta calamidad pública, la moralidad de los individuos debe suplir su insuficiencia. Es usted bastante razonable, querida, como para no entender esto. Es preciso que renuncie a su proyecto de matrimonio por el bien de todos y, sobre todo, por el suyo, pues qué sería de usted, dígame, una vez casada y convertida en madre, sin otro recurso que un salario que puede

${ }^{8}$ Le Jourmal du Dimanche núm. 59, 14 de diciembre de 1856.

Sobre el costo de los niños: "Como responsable de la familia, con cinco o seis pequenosos a los que había que darles de comer y con una mujer eclenque, jamás pudo tomarle la delantera a la miseria." Mérouvel, Abandonnée (Abandonada), 2a. parte, cap. II. "Son pobres y calculan la carga que el pequeño ser por venir va a imponerles; piensan en cl trastocamiento de su presupuesto." Mérouvel, La fille sans nom (La muchacha sin nombre), cap. XLIX. Pero aqui no estamos cerca del Frapié de La maternelle (La maternah), sino, tal vez, del Pérochon de Le creùx-de-maison (Los vacíos de la casa)... 
serle arrebatado por el cese en el trabajo, por enfermedad, por muerte. ¿Ya había reflexionado al respecto ? ${ }^{9}$

$\mathrm{Si}$, en su conjunto, la literatura folletinesca no contabiliza los frutos del matrimonio, sí es la maternidad de una mujer sumisa y se complace en pintar algunos amaneramientos en los que la fecundidad y la educación manifiestan su única identidad. Como disciplina folletinesca, como aventura obstétrica, la mujer, mamífero placentario, vive bajo la férula de cierta naturaleza, según un calendario despiadado. En el reino del relato cotidiano - cárcel de mujeres- esta criatura, animal gestador, se asfixia en la horca de la femineidad, pero debemos señalar, sin embargo, que como mujer de una clase privilegiada casi no tendrá más de dos hijos y que el mayor será, por supuesto, un varón. ${ }^{10}$ La familia numerosa se presenta como un hecho de comparzas, como una rareza populachera que sigue el ejemplo de Lestiboude , "quien halló que su familia era insuficiente y creyó que era su deber aumentarla con dos bebés, lo que aumentó a diez el número de sus hijos"."

${ }^{9}$ E. Souvestre, La Chanteuse et le Forcat ou les deux Misères (La cantante y el forzado" las dos miserias), (ap. XXVI. Del mismo P. Sauniérc, Le Roi misère (El rey miseria), la. parIC, (ap). IV; P. Féval, Les partenus (Los arrivistas), cap. XX; E. Moret, Les femmes martyres (Las mujeres mártires), 2a. parte, cap. I: "2(...) son los pobres los que nunca deberían (asarse. - Por qué:? - preguntó una mujer que habia bajado de la barrera de Courcelles para asistir a la salida de los recién casados - Acaso no basta con ser pobre y estar prirado de todos los goces? 'Es preciso que también se consagren al celibato? '.... - - F.ntre los pobres los niños siempre cligen un mal día para llegar. Es como si fucra a propósito. Y además llegan a menudo -añadió otra mujer".

1" Si da a luz más de tres niños morirá, a menudo durante el parto. Cl. R. de Pont-Jest, Sang . Haudit (Sangre maldita). En Les. Mystères du peuple ou Histoire d'une Famille de prolétaires a lravers les iges (Los misterios del pueblo o historia de una familia de proletarios a tran's del tiempo). Introducción, cap. VII, Sue cita a Strabon: "Läs gálicas son fecundas y buenas educadoras", pero la señora Lebrenn, gálica de 1848 , no tiene más que dos hijos; una niña, Vélleda, y un niño, Sacrovir...

"J. Mary, La .Momtreuse de Marionnettes (La titiritera), 3a. parte, (ap. IV. Aunçue es un personaje un tanto abandonado a continuación, se nos presenta al señor Parapet como a padre de nueve hijos. ¿ Se debe a que es el esposo de una lánguida criolla a' G. de Weede, Ia déshérité (La desheredada), cap. I.

En lo esencial los hijos de familias numerosas ofrecen algunas posibilidades dramáticas, intercambios criminales u otras variaciones teatrales: "-Debe haber, hay seguramente familias pobres $y$ honorables que dejarian a uno de sus hijos acceder a la fortuna, que renunciarian a todo para siempre ; con tal de que fuese bien tratado! ; E.sto debe ser algo común! ¡Cuántas viudas o viudos están impedidos para educar a un hijo si tienen seis u ocho! No osan abandonarlo a la asistencia pública ipero estarian encantados de ser exonerados de ese fardo!" J. de Gastỵe, Le secrel du condamné ' f.l secreto del condenado). 
Que se recuerde en este punto al señor Crépin, personaje de Toppfer, que fue consumido por la educación de sus once hijos, todos los cuales tenían el "chichón del gorrión bobo"...

Al desarrollarse en una población política y numéricamente óptima, el folletón casi no se preocupa de los problemas demográficos, pero se inquieta con la disolución de la célula familiar, con los problemas educativos ligados al niño:

La familia ha caído tan bajo en el orden moral y en su propia estima que aquellos que son su cabeza y su corazón ni siquiera osan asumir la gran responsabilidad de educar a sus hijos. Mientras más vida familiar haya más enseñanza paterna y vigilancia materna habrá. Independientemente de que sea usted obrero, burgués o gran señor, el niño le pesa, su presencia lo fatiga y su mirada lo distrae del gran, único y divino pensamiento del becerro de oro, que es el único objeto digno de su nueva religión, mientras que el niño es puesto en manos venales que lo modelan por una monedas al día". ${ }^{12}$

Un universo semejante ignora al neomalthusianismo. Sólo Hector France, compañero folletinista de Liard-Courtois y Humbert, profesa, en la ambigüedad de los Mystères du monde (Misterios del mundo) -mármoles quebrados del soñador Sueesta oscura doctrina:

(...) Aquellos que empujan al aumento de la población (...) son por lo menos imprevisores. Lo hacen con miras a un bien, lo sé. Han observado que la población de los estados de Europa aumenta, mientras que la nuestra permanece estacionaria, y al temer ser devorados por un vecino que se vuelve cada día más poderoso hacen este razonamiento: "Hay que oponer el número al número." Quisicran que, al aumentar el número de sus

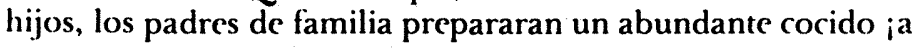

12 J. Loyscau, Histoire t'éridique et surprenante de Rusé III), (Historia v'eridica y sorprendente de Astuto $I I I$ ), cap. XVI (1863).

Mis tarde, de manera complementaria, H. Bordeaux escribirá: "El niño ya no s' estila. No sc casa uno para fundar un hogar, una familia, sino para ser feliz. El niño no e's sino un accidente desagradable. El tipo de felicidad que se busca es ante todo el amor fisico. El marido quiere gozar de su mujer y la mujer de su marido, como si la sa * ciedad no pudiese llegar": La tie an théátre (La irida en el teatro); p. 21. Igualmente La peur de vivere (t)l miedo a vivir), pp. 89-90. 
las descargas de metralla futuras! Pero las madres no dan a luz. sin dolor ni educan con numerosas vigilias y penas a los hombres para hacer de ellos carne de cañón. Sin embargo, esto es lo que amenaza a la futura generación. ¿ Acaso no vale más seguir cl precepto de Malthus y decir: "Absténganse"? Es verdad que si nos abstenemos corremos el fuerte riesto de convertirnos en la presa de nuestros veçinos (...) La tierra es limitada, llegará el día en el que rebosará de demasiados habitantes y, lo repito, al disminuir los campos cada días más bajo el pisoteo humano millones de seres sólo nacerán para matarse unos a otros o para morir por falta de espacio y de subsistencia. Todo esto es tan claro como el sol que brilla en este momento por encima de nuestras cabezas. ${ }^{19}$ todavia hay valientes familias francesas que dan el bello ejemplo de una escasa fecundidad (...) El Petit Journal ha sido uno de los primeros en aportar a estas grandes familias de trabajadores un testimonio efectivo de su interés y de su simpatía". ${ }^{14}$

Curiosamente, la narración folletinesca no se afirmó tan procreadora como su sostén y no colaboró de ninguna manera con las połémicas contra el despoblamiento. Hubo toda una literatura oficial que resurgió con Lannelongue, Nadaillac, Bertillon, etc, ${ }^{15}$ pero el folletín se mantuvo callado.

Sin embargo, como el folletín era patriota no se escuchan voces parecidas:

13 H. France, Les Mystères du monde (Los misterios del mundo), París, Lib. del Progries, sin fecha (1898), 100 entregas, p. 795.

14 Le Petit Journal. Suplemento ilustrado núm. 572, 16 de abril de 1905 (cita de Nadaillac ('n el núm. 181, 7 de mayo de 1894).

"A la baja de la natalidad la acompañan siempre los indices sociales más enojosos. Los perversos sostienen, con el apoyo de sus abominables doctrinas, que la fecundidad engendra la miseria, fuente de todas las deseperaciones. (...) Lo novelesco, tan pernicioso para la paz de los corazones, evita el hogar donde la vida normal y sana ha concentrado todas las aspiraciones sentimentales en torno a las cunas. El niño es la bendición, la protección de la casa (...) un pueblo debe respetar la ley de Dios si no quicre que un.día el extranjero le imponga su ley". La semaine Littéraire núm. 72, 18 de mayo de 1913; de igual manera el núm. 77.

Presentación del programa de Toutée por el scñor Tinayre en L'Illustration núm. 3124, 10 de enero de 1903. Ver las charlas de Jeanne d'Antilly en Le Journal pour Tous, Año VI, núm. 26, 24 de junio de 1896, y Año VIII, núm. 41, 12 de octubre de 1898.

15 "La infecundidad se halla actualmente en el orden del día. Ya sea que nazca de las propagandas malsanas, de las maniobras fraudulentas o de una concepción errónea del ahorro, puesta al servicio de principios económicos llevados al extremo, el 
$-¡$ Eh! ¡eh! señor Gauthier, los cerrajeros no son flojos... He aqui a un niño al que hay que bautizar... pero hay otro en camino... Se dice que Francia se despuebla. Trataré siempre, por mi parte, de que esto sea una mentira... ${ }^{16}$

Y es cierto, pero esta complicidad deshonesta no podría ser confundida con la angustia de un Bertillon... Además, estos comentarios son, según sabemos, de los menos frecuentes. Es la moral y no el poblacionismo, que es un dispositivo del socialismo patriotico, la que vencerá a Alemania. No nos alistó ningún Buonarotti Folletinesco. Así, las numerosas series que pregonan el desquite hablan abundantemente sobre la guerra futura, las alianzas posibles, los armamentos necesarios, pero siguen manteniendo silencio a este respecto, con excepción de esta reflexión de Barthélemy:

(...) se afirma que nuestra raza degenera. Es cierto que en cantidad no se incrementa sino insensiblemente, pero no es menos cierto que progresa en calidad. ¿ De dónde procede su debilidad numérica? De la supresión del derecho de primogenitura, se dice, y se observa con justa razón que la disminución del número de niños se manifiesta sobre todo en las familias con recursos. ${ }^{17}$

desploblamento no deja de ser una terrible plaga contra la que los médicos, los legisladores y los escritores levantan, al parecer vanamente, las fuerzas vivas de su crudición y de su tal'nto". J. Renaud, (Les inféconds (Los infecundos), Paris, Grasset, 1911.

"Lo maravilloso es que, no obstante todas estas trabas, todos estos cálculos, 10 das estas hipocresías, los niños llegan de todas maneras... en menor cantidad de la que seria necesaria, por supuesto, pues el mal, después de haber pasado por la clase media, que se restablece lentamente, alcanza al pueblo inmenso del campo. Pero, en fin, los niños siguen naciendo y es la buena mujer la que triunfa". M. Corday, Mon pettt mari. ma petite femme (Mi maridito, mi mujercita), París, Empis, 1899. Igualmente Sésame ou la maternité consentie (Sésamo o la maternidad asentida), 1903. "Este estudio-que es un resumen del plan de batalla entre prolificos y neomalthusianos- viene a incrementar el pequeño grupo de novelas que se inpiraron en este vasto tema". Ver también Lavedan, la famille française (La familia francesa); Zola, Fécondité (Fecundidad), etc., etc. En 1924 C. Vautel, Madame ne veut pas d'enfant (La señora no quiere hijos); P. Féval, hijo, Ton corps est a moi (Tu cuerpo es mío). En el lado opuesto está V. Margueritte, Vers le Bonheur (Hacia la felicidad) y mucho antes que él R. Emery, La faute nuptiale (La falta nupcial), cuyo prefacio, reproducido por Humbert en La Génération consciente (La generación consciente), fue continuado...

16 J. Mary, La Pocharde (La borracha), 3a. parte, cap. IX. gas, p. 70.

1 H. Barthèlemy, La Guerre (La guerra), Paris, Rouff, sin fecha (1888), 193 entre-

No hay ningún retornelo natalista en Hennebert. Nos soldats (Nuestros soldados); 
Totalmente al contrario, la medicina popular, que es una vulgarización enciclopédica en fascículos, participa, mediante breves señalamientos morales, en la gritería natalista:

Para la sociedad, para la patria, los fraudes genésicos son una verdadera plaga, pues limitan la fecundidad, sin imponer un freno a las ansias sexuales. La población de Francia en particular ha sufrido una suspensión en su crecimiento progresivo, y esto todos los estadísticos lo atestiguan con dolor. ${ }^{18}$

Se trata, pues, de una literatura sentenciosa que rubrica los sortilegios antimalthusianos, los decretos de las ligas moralistas, pero que no numera para nada esos consejos ni da jamás el tamaño ideal de la familia francesa.

Como salvación global el folletín no puede tolerar la enseñanza de Malthus. Al inscribirse en una lógica filantrópica soberana el epílogo establece derechos inalienables para todos y, como medida de salubridad, recrea nuevas solidaridades, santifica a la comunidad endogámica. Como comercialización de sueños simples que anuncian la realización de una convivialidad particular el texto cotidiano se desarrolla como literatura del matrimonio moral. Hay que decirlo: el malthusianismo no es una conquista folletinesca...

Biot y Massard, La France et la Russie contre la triple Alliance (Francia y Rusia contra la triple alianza); X, la prochaine guerre par un soldat (La próxima guerra, por un soldado), y Danrit, como conclusión a La Guerre fatale (La guerra fatal), se contenta con decir: "(...) envianos a tus hijos, nosotros te los devolveremos fuertes, disciplinados, armados para la existencia".

Scñalcmos aquí que, después de 1918, apareció cierto número de obras sobre el celibato lemenino como consecuencia de la guerra. Cf. G. Duhamelet, Les Inépouséts (Las que no ie casaron).

18 A. Clerc, Hrgiène et médecine de deux sexes (Higiene y medicina de los dos sexos). Paris, Roult, 265 (ntregas, p. 303.

Desete el comicuzo del mundo la naturaleza abrió el gran libro de la reproducción y todos los seres vivos leyeron en él la orden siguiente: Creced y multiplicaos. A esta ley sagrada, promulgada por la naturaleza, los deberes del ciudadano añaden algo más: Sean tutiles a la patria, déjenle hijos cuyos servicios, al recordarle la existencia de ustedes, harain bendecir su memoria. Se debería privar de tumbas a los hombres que remuncian voluntariamente al dulce nombre de padre y, al contrario. escribir sobre la tumba de los verdaderos ciudadanos: ¡Aqui yace alguien que dio hombres a la patria!" Villomont, Les secrets de la génération (Los secretos de la procreación). p. 517. Consultar: Deville, Médecine pratique el populaire (.Medicina piráctica y populart; Labarthe, Diction- 
naire populaire de médicine usuelle d'hygiène publique et privée (Diccionario popular de' médicina usual para la higiene pública y privada); Villemont, L'amour conjugal (El amor conyugal). J. Rengade en La vie normale et la santé (la vida normal y la salud) y Les grand maux et les grands. remèdes (Los grandes males y los grandes remedios) parece no abrazar esta causa...

Según sabemos, el folletín no se interesa en la eugenesia tal y como la presenta Adolphe Mary en su novela Julie de Noiront, en donde poscribe a cualquier persona que pade\%a alguna enlermedad crônica. En sus relatos los jorobados jamás se casan y a menudo son criminales... 